\title{
Positive Psychologists on Positive Psychology: Ed Diener
}

Interview by

Aaron Jarden

\begin{abstract}
Ed Diener, a.k.a. 'Dr. Happiness', is Joseph R. Smiley Distinguished Professor of Psychology at the University of Illinois and senior scientist at Gallup. He has over 300 publications, with about 200 being in the area of the psychology of wellbeing, and is one of the most highly cited psychologists with over 30,000 citations.
\end{abstract}

\section{In general terms and in your mind, what are some of the defining features of positive psychology?}

One defining feature of positive psychology is a desire to study positive aspects of human behavior and functioning; aspects of life that make it happier, more peaceful, and more desirable in general. Although there are some cultural differences in what might be considered 'good' or desirable behavior, there is certainly some consensus too. Everywhere in the world, people want to be happy, to get along with other people, to have their needs met, to develop and grow, and to have respect. People want to love and to be loved. It is these universals that we want to study as positive psychologists. Of course people did study these things even before the advent of positive psychology, but the level of interest shown was much less than the interest shown in negative behavior, in problems. The second defining feature of positive psychology is that we are attempting to build it on a scientific base. Many people talk about positive behavior, and try to increase it-from politicians to religious leaders to youth clubs. These are usually good things. But we want something new - the study of positive behavior using scientific methods. As the science grows, we will then be in a position to test interventions scientifically as well.

\section{Can you tell me about your work in positive psychology, particularly around subjective wellbeing and happiness?}

I began studying subjective wellbeing, 'happiness', in 1981. For the first 10 years there were only a few pioneers working quietly in the area, and we received little attention. We were a backwater research area. In the 1990s we started to receive more notice, and more researchers entered the field. In the late 1990s positive psychology was founded by Martin Seligman and others, and this created more research in our field. In other words, positive psychology research and practice occurred before the positive psychology movement, but the movement gave this research a big boost. All of a sudden more attention and interest flowed to these positive research topics. We initially used the Experience Sampling technique in the early 80s to study people's moods across time and situations. At that time there was a lot of focus on

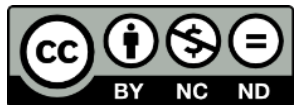


demographic factors such as income and sex, but we paid careful attention to personality, and how it affected people's happiness. We looked at a broad range of personality traits such as extraversion and self-esteem, but we also examined people's goals, aspirations, and social comparisons. In the 90 s we began to look more systematically across cultures to see if some societies were happier, and whether the same factors predict subjective wellbeing in different cultures. Not only did we find that some societies tend to be happier than one might expect, such as the Latin American nations, but we also found that certain variables predict happiness more strongly in some cultures than in others. For example, my daughter Marissa and I found that self-esteem is a stronger predictor of life satisfaction in individualistic nations than in collectivistic ones. We have continued these lines of research to the present, but we also have begun to look more carefully at the outcomes of subjective wellbeing-are happy people healthier, more productive, and do they experience better social relationships? What we have found has surprised me. Not only is happiness a pleasant state, but in most ways it is a particularly helpful one. For instance, happy people are healthier and live longer. They have better social relationships and stay married longer. They volunteer more, and they are better citizens at work. Some of our work even finds that they make more money. When I started I was not Pollyanna, I was skeptical of some of the claims made for the benefits of happiness. Of course these claims have occasionally been exaggerated, but by and large I have become convinced that a general happy state is a very good one in terms of success in life.

\section{Is there any new knowledge or studies around happiness you would like to highlight that you think are cutting edge?}

We are finding out more and more about happiness around the globe. Two decades ago very little was known. We now know a great deal about which cultures are happiest and unhappiest, and some of the causes. For instance, we know that not having your basic needs met leads to low life satisfaction, and that corruption and other social interactions that lead to distrust lead to low levels of positive feelings. We also know that although a high income is associated with high life satisfaction across nations, other factors such as health and peace also lead to higher life satisfaction. An interesting thing is that some predictors of happiness are universal, such as having basic needs met, and having others one can count on for help. But there are some predictors of happiness that seem to be stronger in some cultures than in others. Self-esteem is a much stronger predictor of happiness in individualistic cultures compared to collectivistic cultures, for example. Another area of research that I am proud of is the development of new scales for use in positive psychology, and research showing the validity of these scales. We first developed a scale to assess life satisfaction, and showed that this scale has a strong level of reliability and validity. We have also developed a scale to measure feelings and emotions. A very short scale we created is designed to assess human flourishing by quickly tapping people's feelings that their life is meaningful, that they have supportive family and friends, and so forth. This scale is very short, and therefore can easily be added to studies without taking up much time. All these scales are available on my website.

\section{Your proudest moment in the field?}

I recently received the American Psychological Association's Distinguished Scientist Award, and this was very rewarding. But my proudest moments have come not from awards, but have come in seeing what my family and my students have accomplished. My wife and three of our children are psychologists, and this is a great thing for a father. We never tried to convince our kids to become psychologists, we never even mentioned it. But they saw how much we loved 
it, and that apparently drew them to it. In terms of my former students, many of them are turning out to be stars. They are doing such important research and accomplishing so much. Beyond research they are becoming journal editors and department chairs. This gives me great joy.

\section{Which discipline do you think positive psychology can learn most from moving forward?}

We can learn from every discipline, from neuroscience to anthropology to sociology. But the discipline I am learning a lot from is economics, and this surprises me. Economists have sometimes overstressed the importance of money in happiness. However, we do need money in the modern world to meet our needs and to develop and to do interesting things. So money can be beneficial to happiness. But what I have learned from economists is an objective approach to problems and a reliance on data. Too often in positive psychology people think they already know the answers to questions, or gain the answers from their intuitions. My fear is that positive psychology should not be the province of well-meaning people with strong opinions, without a scientific base for those opinions. I have found that economists really take a hard look at data, and they are often quite objective about that. I admire this aspect of economics.

\section{Positive psychology is being applied in health, education, the army, in therapy, or more recently at the governmental level with a focus on assessment. Where next? Are there fields and areas that positive psychology is beginning to move into and gain traction?}

One of the really important applied movements is 'national accounts of wellbeing'. Martin Seligman and I rekindled interest in this with our 2005 article, Beyond Money (Psychological Science in the Public Interest). We argued that governments need to measure various forms of psychosocial wellbeing to complement the measures of economics that all governments collect. People pay attention to what is measured, and right now the economies of nations get the lion's share of attention. Indeed, I would guess that the economy receives about 90 percent of the attention of politicians and the news media. National accounts of wellbeing are able to give a broader view of quality of life, and how citizens are faring.

We are seeing progress across the globe. The prime minister of the United Kingdom announced that wellbeing would become a concern of the government, and instituted a set of simple measures that would be collected in his country. Other nations are following suit, and the Organization of Economic Cooperation and Development (OECD) is devising a set of prototype measures. I see this as the most important advance in applied positive psychology. Measuring wellbeing might not seem as exciting as going out and intervening to make people happier or more virtuous. However, the national accounts promise to have a very widespread effect. In their ability to capture the interest of the entire population, they can provide leverage for many different types of changes in society that go far beyond the work of individual positive psychologists. I have my fingers crossed.

\section{What's one aspiration you have for positive psychology?}

My strongest desire for positive psychology is that it not be a cult or a club. Too often positive psychologists just look at the work of other positive psychologists, rather than broadening out and looking at relevant work of those who are not in the positive psychology fold. Too often people look at a handful of leaders for what positive psychology is, and what other positive psychologists say about an issue. Instead, we need to examine both what positive psychologists 
say and also what others who have studied that topic have to say. There is a great deal of valuable material about positive psychology coming from people who are not 'members' of the positive psychology movement. If we don't pay attention to this work, positive psychology will never flourish.

\section{One piece of advice for aspiring positive psychology students, researchers or practitioners?}

I have two pieces of advice for aspiring positive psychologists. First, although work in this field is fun, it takes a lot of hard work and perseverance. Some people pop into the field thinking that they will find magical and quick answers. Instead, in a developing field such as this one we are searching for answers, and this requires deep thought and hard work. My second piece of advice is to build your work on science. Listen to what other positive psychologists say, but always remain critical and a bit skeptical. Learn to think for yourself. I see many young people who want to find out what the leaders of positive psychology think so they will know the truth. We are not at that point yet. You need to listen to the experts, but also look at the evidence and think for yourself.

\section{Author}

Aaron Jarden

Open Polytechnic of New Zealand

aaron.jarden@openpolytechnic.ac.nz 